Submitted, accepted and published in

International Journal of Hydrogen Energy 37 7141-7151 (2012); ISSN 0360-3199, http://dx.doi.org/10.1016/j.ijhydene.2011.11.090

\title{
Gas diffusion electrodes for methanol electro-oxidation studied by a new DEMS configuration: Influence of the diffusion layer.
}

S. Pérez-Rodríguez ${ }^{1}$, M. Corengia ${ }^{2}$, G. García ${ }^{3 *}$, F.C. Zinola ${ }^{2}$, M.J. Lázaro ${ }^{1}$, E. Pastor ${ }^{3 *}$ ${ }^{1}$ Instituto de Carboquímica (CSIC), Miguel Luesma Castán 4, 50018 Zaragoza.

${ }^{2}$ Instituto de Química Biológica, Facultad de Ciencias, Universidad de la República del Uruguay, 11400 Montevideo, Uruguay.

${ }^{3}$ Universidad de La Laguna, Dpto de Química-Física, Avda. Astrofísico Francisco Sánchez s/n, 38071 La Laguna (Tenerife).

$\left(^{*}\right)$ Corresponding author:

G. García: Tel.: +34 91585 4778; Fax: +34 91585 4760; E-mail address: gonzalo@icp.csic.es; Current address: Instituto de Catálisis y Petroleoquímica, CSIC, c/ Marie Curie, 2. 28049 Madrid (Spain).

E. Pastor: Tel.: +34 92231 8071; Fax: +34 922318002; E-mail addres: epastor@ull.es. 


\begin{abstract}
A novel differential electrochemical mass spectrometry (DEMS) cell has been developed to study gas diffusion electrodes (GDEs) used in fuel cells under operating conditions. In this way, catalytic and diffusion properties of the electrodes can be evaluated at the same time. Moreover, DEMS, allows the detection of volatile and gaseous products and intermediates generated in the electrochemical reactions with good sensitivity. In this way, $\mathrm{CO}_{2}$ conversion efficiencies are evaluated during alcohol oxidation reaction. In the present communication, the electrochemical behaviour towards hydrogen evolution and $\mathrm{CO}$ and alcohol electrooxidation at different platinumbased catalysts has been studied using the new DEMS cell configuration. The relative yields of $\mathrm{CO}_{2}$ and by-side products during methanol oxidation have been evaluated to determine the $\mathrm{CO}_{2}$ conversion efficiency. In addition, the diffusional properties of diverse GDEs have been considered.
\end{abstract}

Keywords: DEMS, PEMFCs, GDEs, GDLs, CO stripping, MOR 


\section{Introduction}

Among the different types of fuel cells, polymer electrolyte fuel cells (PEMFCs) are the most promising for both portable and stationary applications due to its high power density at low temperatures $\left(55-95^{\circ} \mathrm{C}\right)$, low weight, compactness and suitability for discontinuous operation [1-4]. The main part of a PEMFC is the membrane-electrodeassembly (MEA), composed by two gas diffusion electrodes (GDE), and the polymer membrane, which acts as the electrolyte. Normally, the GDE is constituted by a gas diffusion layer (GDL) and a catalytic layer. The main function of the GDL is to transport the reactants and products to and away the catalytic layer. On the other hand, the fuel (e.g. $\mathrm{H}_{2}$ ) generates protons at the anode that flow trough the polymeric membrane towards the cathode to form water with oxygen (pure or from the air), while the produced electrons flow through an external circuit. However, if an organic molecule (e.g. $\mathrm{CH}_{3} \mathrm{OH}$ ) is used as fuel, several intermediates and by-side products (e.g. carbon monoxide, formaldehyde and formic acid) can be formed in addition to protons and carbon dioxide. In this sense, the GDL is a very important topic in the PEMFCs due to its great importance for delivering reactants to the catalysts and for liberating catalytic sites by removing in an appropriated way the products and by-side products. Moreover, a suitable GDL becomes necessary in order to avoid the flooding in the GDE when the PEMFC is under operational conditions.

In the last years, catalyst development for PEMFCs has concerned many investigations [1-14] and many characterization techniques have been reported elsewhere $[1,6,8,15$ 17]. However, in most cases these techniques evaluate the catalytic activity in different conditions from those in real fuel cells (i.e. a catalyst powder onto a glassy carbon disk 
$[8,18,19]$ or onto a gold-covered tantalum strip [20]). Therefore, it becomes necessary to seek other strategies to investigate the catalytic and diffusion properties of GDEs in fuel cells conditions under operating conditions. For this purpose, recently our research group has developed a novel differential electrochemical mass spectrometry (DEMS) cell, which allows the study of GDEs. This configuration provides further information, such as reaction product distribution, interaction with the diffusion layer and the diffusional properties of the reactants and products within this layer. Therefore, with this technique, catalytic and diffusion properties can be evaluated at the same time. Moreover, DEMS provides more information than a simple electrochemical technique, allowing the detection of volatile and gaseous products and intermediates generated in the electrochemical reactions with excellent sensitivity [20-22]. Thus, $\mathrm{CO}_{2}$ conversion efficiencies, as well as reactants/products diffusion can be evaluated during the alcohol (e.g. methanol) oxidation reaction.

In this work, the new DEMS cell configuration was tested through the hydrogen evolution reaction. After that, two important reactions in the fuel cell field were examined: adsorbed $\mathrm{CO}\left(\mathrm{CO}_{\mathrm{ad}}\right)$ and methanol electrooxidation at different Pt catalysts supported on Vulcan XC-72R. The relative yields of both $\mathrm{CO}_{2}$ and $\mathrm{HCOOH}$, during the methanol electrooxidation, were measured to determine the $\mathrm{CO}_{2}$ conversion efficiency. The Pt catalysts supported on Vulcan XC-72R were prepared by two different methods, with the finality of studying and comparing the influence of the synthesis method on the performance of the catalysts. In addition, electrochemical properties of both catalysts were compared with that of a commercial Pt/Vulcan XC-72R catalyst (E-TEK). 
On the other hand, the diffusional properties of the GDEs were evaluated by the new DEMS cell configuration, using for this purpose different GDLs (i.e. increasing the amount of the carbon + PTFE ink) and compared with a commercial GDL (Hydro2Power).

\section{Experimental}

\subsection{Synthesis of the carbon-supported Pt electrocatalysts}

The carbon-supported Pt electrocatalysts were prepared by two different methods, using: i) sodium borohydride as reducing agent (BM); and ii) ethylene glycol (EGM) as solvent and reducing agent. Appropriate amounts of metal precursor were employed to obtain a theoretical platinum loading of $20 \mathrm{wt} . \%$ on the carbon material, Vulcan XC72R, supplied by Cabot. Chloroplatinic acid (8 wt. $\% \mathrm{H}_{2} \mathrm{PtCl}_{6} \cdot 6 \mathrm{H}_{2} \mathrm{O}$ solution, SigmaAldrich) was used as metal precursor.

In the $\mathrm{BM}$ reduction method, catalyst was prepared by impregnating the carbon with the metal precursor solution. Subsequently, the metal was reduced with a $26.5 \mathrm{mM}$ sodium borohydride (99\%, Sigma-Aldrich) solution, which was slowly added to the precursor one under sonication. [23].

In the EGM reduction method, the metal precursor was dissolved in ethylene glycol (1mL EG/1mg Pt) under sonication and the $\mathrm{pH}$ was adjusted to 11 adding $1 \mathrm{M} \mathrm{NaOH}$ solution. After that, the carbon support was added and the resulting mixture was treated 
at $195^{\circ} \mathrm{C}$ for $2 \mathrm{~h}$ and subsequently quickly cooled in a cold water bath. The $\mathrm{pH}$ was measured and adjusted to 1 using $\mathrm{HCl}$ (37\%, Sigma-Aldrich) [24].

The catalysts were named as Pt/Vulcan-BM, Pt/Vulcan-EGM and E-TEK for the commercial one.

\subsection{Preparation of working electrodes}

GDEs were used as working electrodes ( $7 \mathrm{~mm}$ of diameter). The working electrodes were prepared depositing a layer of $2-3 \mathrm{mg} / \mathrm{cm}^{2}$ of diffusion ink onto both sides of a carbon cloth and a layer of the catalyst ink onto one side.

The gas diffusion ink was prepared mixing Vulcan XC-72R, ultrapure water (Millipore Milli-Q system), isopropanol (Merck, p.a.) and a PTFE dispersion (60 wt. \%, Dyneon) until resulting in a $20 \mathrm{wt} . \%$ PTFE mixture. Carbon cloth was painted with this diffusion ink, and subsequently, was treated at $320^{\circ} \mathrm{C}$ for $1 \mathrm{~h}$.

Catalyst inks were prepared by mixing the respective electrocatalysts with Nafion dispersion (5 wt.\%, Sigma-Aldrich) and ultrapure water (1:5:10 wt.) and deposited onto one side of the GDE. Final metal loading of the working electrodes was of $0.4 \mathrm{mg}$ $\mathrm{Pt} / \mathrm{cm}^{2}$ electrode.

In the case of the commercial catalyst, E-TEK, with the purpose of evaluating the diffusion properties of the electrodes, three different electrodes were prepared changing 
the diffusion conditions, using: i) a layer of $2-3 \mathrm{mg} / \mathrm{cm}^{2}$ of diffusion ink onto both sides of the carbon cloth; ii) the same layer but onto only one side of the carbon cloth; and iii) a commercial diffusion layer (20 wt.\% PTFE onto one side of the carbon cloth, Hydro2power). The electrodes were named E-TEK, E-TEK 1GDL and E-TEK commercial GDL. Tab. 1 summarizes the nomenclature used for all the gas diffusion electrodes prepared.

\subsection{Physicochemical characterization}

Catalysts were also characterized by energy dispersive X-ray analysis (EDX) to determinate the real metal load and X-ray diffraction (XRD) to evaluate the crystallographic properties of the materials. Metal content of the electrocatlysts was obtained using a Hitachi S-3400N microscope coupled to a Röntec XFlash analyzer. XRay diffraction (XRD) patterns were recorded using a Bruker AXS B8 Advance diffractometer with $\theta-\theta$ configuration and using $\mathrm{Cu} \mathrm{K} \alpha$ radiation.

\subsection{DEMS set-up}

A scheme of the developed DEMS cell is shown in Fig. 1. As can be seen, the working electrode (WE) is fixed between a PTFE membrane (Scimat) and a carbon glassy rod, which is connected to a Au wire to keep the electrical contact. The cell was designed to follow "in-situ" the electrochemical and diffusional properties of electrodes prepared by different methods, and simultaneously, to detect the gaseous and volatiles species produced on the electroactive surface through mass spectrometry. In this way, the experimental set-up allows the simultaneous acquisition of mass spectrometric cyclic 
voltammograms (MSCVs) for selected $\mathrm{m} / \mathrm{z}$ (mass to charge) ratios and conventional voltammograms (CVs) or simultaneous mass spectrometric current transients (MSCTs) and conventional current transient curves (CTs). Additionally, the cell permits to exchange the electrolyte under control of the WE potential.

\subsection{Mass spectrometric and electrochemical measurements}

DEMS experiments were carried out in a three electrodes electrochemical cell, at room temperature and atmospheric pressure. The counter electrode was a high surface area carbon rod and the reference electrode was a reversible hydrogen electrode (RHE) placed inside a Luggin capillary. All potentials in the text are referred to this electrode. The potenciostat-galvanostat used was an Autolab PGSTAT302 (Ecochemie). The cell was directly attached to the vacuum chamber of the mass spectrometer (Balzers QMG112) with a Faraday cup detector. Argon (N50) was used to deaerate all solutions and $\mathrm{CO}(\mathrm{N} 47)$ was employed for the adsorption experiences. Sulphuric acid (0.5 M, Merck p.a.) and methanol (0.1 M, Merck p.a.) were used for the preparation of the base electrolyte $\left(0.5 \mathrm{M} \mathrm{H}_{2} \mathrm{SO}_{4}\right)$ and the working solutions, respectively.

First, several potential cycles between 0.025 and $0.9 \mathrm{~V}$ in $0.5 \mathrm{M} \mathrm{H}_{2} \mathrm{SO}_{4}$ during electrolyte exchange, previously deaerated with Ar, were recorded, at $100 \mathrm{mVs}^{-1}$, to clean and activate the electrode surface. After that, in situ DEMS experiments were carried out.

CTs and the corresponding MSCTs for hydrogen evolution for each electrode were recorded in $0.5 \mathrm{M} \mathrm{H}_{2} \mathrm{SO}_{4}$ at the beginning of the experiments, with the purpose of 
calculating the delay or detection time of the novel cell setup. The potential was stepped from $0.4 \mathrm{~V}$ to $0.0 \mathrm{~V}$ and then switched back to $0.4 \mathrm{~V}$ after $60 \mathrm{~s}$. Other authors have used this technique to estimate the response time of the spectrometer [25-27]. In addition, CVs and MSCVs for hydrogen for each electrode at different scan rates (10, 20, 50 and $100 \mathrm{mVs}^{-1}$ ) in $0.5 \mathrm{M} \mathrm{H}_{2} \mathrm{SO}_{4}$, were also registered to evaluate the detection time of the cell set-up.

Electrochemical active areas of the electrodes were estimated from CO-stripping voltammograms by the integration of an adsorbed $\mathrm{CO}$ monolayer $\left(\mathrm{CO}_{\mathrm{ad}}\right)$ oxidation, assuming a charge of $420 \mu \mathrm{C} \mathrm{cm}^{-2}$ involved in the oxidation of a monolayer of linearly adsorbed CO. These electroactive areas have been used to calculate the current densities $\mathrm{J}\left(\mathrm{A} \mathrm{cm}^{-2}\right)$ given in the text. $\mathrm{CO}$ was adsorbed on electrode surfaces by bubbling this gas through the electrolyte for $10 \mathrm{~min}$ at $0.10 \mathrm{~V}$. The excess of $\mathrm{CO}$ was then flushed from the electrolyte with Ar during 30 min and the potential was cycled between 0.025 and $1.000 \mathrm{~V}$ at $0.005 \mathrm{~V} \mathrm{~s}^{-1}$ for three complete cycles. During CO-stripping experiments, mass signals of $\mathrm{H}_{2}(\mathrm{~m} / \mathrm{z}=2)$ and $\mathrm{CO}_{2}(\mathrm{~m} / \mathrm{z}=44)$ were followed.

Methanol oxidation reaction (MOR) was studied by cyclic voltammetry and chronoamperometry. CVs were recorded in $0.5 \mathrm{M} \mathrm{H}_{2} \mathrm{SO}_{4}+0.1 \mathrm{M} \mathrm{CH}_{3} \mathrm{OH}$ solution between 0.025 and $1 \mathrm{~V}$ at a scan rate of $0.005 \mathrm{~V} \mathrm{~s}^{-1}$. Current transients were recorded in the same solution at $0.55 \mathrm{~V}$ (a typical value for the anode of PEMFCs under operational conditions) during $600 \mathrm{~s}$. In the course of methanol oxidation experiments, mass signals of $\mathrm{CO}_{2}(\mathrm{~m} / \mathrm{z}=44)$ and formic acid (followed through methylformate formation, $\mathrm{m} / \mathrm{z}=$ 60) were recorded. 


\subsection{DEMS calibration}

The calculation of the efficiency for methanol conversion to $\mathrm{CO}_{2}$ by DEMS requires a previous determination of the $\mathrm{m} / \mathrm{z}=44$ calibration constant $\left(K^{\mathrm{CO}_{2}}\right)$. With this purpose, faradic $\left(Q_{f}^{\mathrm{CO}_{2}}\right)$ and ionic $\mathrm{m} / \mathrm{z}=44\left(Q_{i}^{C O_{2}}\right)$ charges were obtained from CO stripping and related according to the equation: $K^{\mathrm{CO}_{2}}=\left[2 \frac{Q_{i}^{\mathrm{CO}_{2}}}{Q_{f}^{C \mathrm{O}_{2}}}\right]$. The factor 2 refers to the number of electrons needed for formation of one $\mathrm{CO}_{2}$ molecule from $\mathrm{CO}_{\mathrm{ad}}$. This constant has to be determined before each experiment because it depends of several variables (membrane electrode gap, flow rate, temperature and pressure in the mass vacuum line) and it has to be fixed during the experience.

Then, the current efficiency $E$ for methanol electrooxidation to $\mathrm{CO}_{2}$ is determined from the subsequent expression: $E^{\mathrm{CO}_{2}}=\left[6 \frac{Q_{i}^{\mathrm{CO}_{2}}}{K^{\mathrm{CO}_{2}} Q_{f}^{T}}\right]$, where 6 are the electrons involved in the complete oxidation reaction, $Q_{f}^{T}$ is the charge associated to all faradic processes occurring at the surface during methanol electrooxidation (obtained from the current transient) and $Q_{i}^{C O_{2}}$ is the charge associated to the $\mathrm{m} / \mathrm{z}=44$ signal recorded during the MOR.

\section{Results}

\subsection{Physicochemical characterization of the electrocatalysts}


EDX analysis showed that all catalysts presented a metal content similar to the nominal value of $20 \%$.

Fig. 2. shows the XRD pattern for Pt/Vulcan-EGM catalyst as example. As can be seen, a peak around $2 \theta=25^{\circ}$ was observed, which is associated to the graphite (002) diffraction line. This peak is attributed to the turbostratic structure of the primary particles of the support, Vulcan XC-72R. It can be also observed the five characteristic diffraction peaks of platinum at $2 \theta=40,47,67,81$ and $85^{\circ}$. These peaks are associated to the (111), (200), (220), (311) and (222) crystallographic planes, indicating that the platinum present the typical face-centered cubic (fcc) structure. All the samples present similar diffractograms.

\subsection{Estimation of the detection time}

The current transient curve (black line) and the corresponding mass signal for hydrogen $(\mathrm{m} / \mathrm{z}=2)\left(\right.$ red line), in $0.5 \mathrm{M} \mathrm{H}_{2} \mathrm{SO}_{4}$, for E-TEK electrode prepared with 2GDLs are shown in Fig. 3. CTs associated with MSCTs are the most appropriate way to analyse the necessary time for detection of volatile products into the mass spectrometer. The potential was steeped from $0.4 \mathrm{~V}$, where hydrogen evolution is not produced, to $0.0 \mathrm{~V}$, where a clear molecular hydrogen formation is produced onto the working electrode. As can be seen in Fig. 3, the mass signal for hydrogen evolution follows the cathodic current immediately. Comparing both curves is possible to estimate the time delay of the cell set-up for the detection of molecular hydrogen formation. Therefore, as the cathodic current peak becomes apparent at $30.422 \mathrm{~s}$ and the $\mathrm{m} / \mathrm{z}=2$ signal indicating the beginning of hydrogen formation at $31.172 \mathrm{~s}$., the delay in the detection of hydrogen 
molecules is ca. $0.75 \mathrm{~s}$. In this sense, it is important to know that a typical DEMS apparatus has a delay detection time around $0.50 \mathrm{~s}$. Therefore, the new cell set-up has an optimum design to study the catalytic and diffusion properties of GDE usually employed at PEMFCs.

After that, with the purpose of studying the effect of the GDL onto the hydrogen diffusion, the same experiments were performed using the same catalyst (Pt/C 20\% wt., E-TEK ), but with different diffusion conditions: with only one diffusion layer (Fig. 4A) and with a commercial diffusion layer (Fig. 4B). It is observed that with one diffusion layer the detection time is negligible (less than the data acquisition time of the potentiostat), while with the commercial GDL is ca. $0.70 \mathrm{~s}$. Therefore, it is important to remark that, the new DEMS cell configuration can discriminate properly the diffusional properties of the diverse GDLs utilized.

In order to verify these results under potentiodinamic conditions, CVs and the corresponding MSCVs for hydrogen were recorded for each electrode. The upper panels of Fig. 5 show the $\mathrm{CV}$ recorded at $0.01 \mathrm{Vs}^{-1}$ in $0.5 \mathrm{M} \mathrm{H}_{2} \mathrm{SO}_{4}$ for the electrodes prepared with two GDLs. In all the cases, a good definition of the hydrogen adsorption/desorption region, as well as the hydrogen evolution feature can be observed. The middle and bottom panels of Fig. 5 display the current density and the mass signal for hydrogen $(\mathrm{m} / \mathrm{z}=2) v s$. time obtained from a complete CV and MSCV, respectively, for each electrode. Comparing both curves is possible to estimate the delay between the ionic and faradaic current associated to molecular hydrogen formation. For example, for the Pt/Vulcan-BM electrode, the faradaic and ionic current peaks appear at $187.781 \mathrm{~s}$ and 188.593 seconds, respectively, so the delay time needed for a volatile molecule of hydrogen to be detected by the spectrometer is less than 1 second. Similar results were 
obtained for the other electrodes. Also, it is noticeable the fast decay of the $\mathrm{m} / \mathrm{z}=2$ signal. So, it is confirmed that no diffusion problems are detected during the hydrogen evolution reaction.

Due to the low delay time of the present cell set-up, higher scan rates can be used to follow the hydrogen evolution. Fig. 6 presents the CVs for a selected electrode, E-TEK with one GDL, at different scan rates $\left(0.01,0.02\right.$ and $\left.0.05 \mathrm{~V} \mathrm{~s}^{-1}\right)$. As it can be seen, higher scan rates lead to an increase in the detection delay time, but even for the highest value, $0.05 \mathrm{Vs}^{-1}$, the detection delay is less than 2.5 seconds. Additionally, Fig. 7 shows the results obtained using the same electrode recorded at very slow scan rate, such as $0.005 \mathrm{Vs}^{-1}$. It is remarkable that, even at this slow scan rate it is not observed any complication (e.g. ohmic drop) related to the cell set-up.

\subsection{CO electrooxidation}

CO-stripping voltammetry can be used to characterize the catalyst surface, as well as, to establish their tolerance towards $\mathrm{CO}$ poisoning. $\mathrm{CO}$ stripping voltammograms were performed for all the catalysts used in the present work at room temperature in $0.5 \mathrm{M}$ $\mathrm{H}_{2} \mathrm{SO}_{4}$ (Fig. 8). It is observed that the peak associated to $\mathrm{CO}$ oxidation for all the catalysts occurs at practically the same potentials, in the $0.78-0.81$ potential range, in accordance with the bibliography $[28,29]$. However, the onset for $\mathrm{CO}$ oxidation shifts to more negative potential for Pt/Vulcan catalysts than for the electrode prepared with

the E-TEK material, demonstrating an improved condition for $\mathrm{CO}$ elimination from these catalyst surfaces. However, no significant differences were observed between the Pt/Vulcan electrodes synthesized by BM and EGM. 
Fig. 9A displays the $\mathrm{CO}$ stripping voltammogram for an E-TEK electrode with two GDLs, and the corresponding MSCV for $\mathrm{CO}_{2}(\mathrm{~m} / \mathrm{z}=44)$. It is observed from the faradaic (middle panels) and ionic (bottom panels) current signals versus time that the time response is similar to the observed with the hydrogen evolution experiment (Fig. 6). Nevertheless, the $\mathrm{m} / \mathrm{z}=44$ signal decay is very slow compared to the hydrogen experiment. The latter behaviour is mainly related to two effects: the high $\mathrm{CO}_{2}$ quantity produced at the working electrode and consequently introduced into the mass chamber; and principally, the slower $\mathrm{CO}_{2}$ diffusion compared with that of hydrogen. So, it is not associated to the cell design, as it was corroborated before through the hydrogen experiments. Moreover, this is the first time for our knowledge that a gas diffusion electrode with a standard catalyst quantity used in PEMFCs is tested by DEMS.

In order to study the GDL effect on the $\mathrm{CO}_{2}$ diffusion, $\mathrm{CO}$ stripping experiments were performed with the same catalyst (Pt/C 20\% wt., E-TEK), but with different diffusion conditions (i.e. different GDLs). For this purpose, the $\mathrm{CO}_{\mathrm{ad}}$ oxidation reaction was performed on GDEs prepared with 1GDL (Fig. 9B), 2GDL (Fig. 9A) and a commercial GDL (Fig. 9C). First of all, it is observable similar mass detection time (less than $1 \mathrm{~s}$. delay) at the onset of $\mathrm{CO}_{\mathrm{ad}}$ oxidation for all the GDEs. However, it is noticeable a different behaviour during the ionic current decay. Thus, in Fig. 9A and 9B, the ionic current tail after the mass signal peak decreases faster due to the lower diffusion path $\mathrm{CO}_{2}$ has to flow, whereas in Fig. 9C the commercial diffusion layer presents the slower ionic current decay, i.e. $\mathrm{CO}_{2}$ needs more time to arrive to the mass spectrometer chamber due to a longer diffusion path. Therefore, it is important to remark that with this novel configuration, DEMS allows the evaluation of the catalytic and diffusion properties of GDEs at the same time. 


\subsection{Methanol electrooxidation}

Fig. 10 shows the CVs for methanol electrooxidation at Pt/Vulcan-BM, Pt/Vulcan-EGM and commercial (E-TEK) catalysts with 2 GDLs. All GDEs present similar features to those reported in bibliography [9,30-32], i.e. a rise in the faradaic current is apparent around $0.40-0.45 \mathrm{~V}$ (onset potential) during the positive-going potential scan, developing an anodic peak whose position depends on the catalyst. After the anodic peak, the current decreases due to the Pt oxide formation, which is not catalytic for the methanol oxidation reaction (MOR). At the negative-going potential scan, a new anodic contribution is observed. The latter occurs at more negative potentials than the Pt oxide reduction, and consequently, re-adsorption and electrooxidation of methanol can happen again $[9,30]$.

Interestingly, Pt/Vulcan electrodes synthesized by BM and EGM methods achieved a similar current density values during the MOR. However, the catalytic activity towards this reaction developed by the commercial catalyst is appreciably lower than the observed by synthetized materials. In this sense, it is well known that the MOR is surface dependent, i.e. first methanol has to adsorb onto a suitable Pt surface (at least three Pt neighbours atoms are needed for this step), afterward it may suffer several dehydrogenation steps, in which reaction intermediates (e.g. $\mathrm{CO}_{\mathrm{ad}}$ ) and by-side products (e.g. formic acid and formaldehyde) can be formed, and last oxidation step should be the removal of reaction intermediates by adsorbed oxygenated species (e.g. $\left.\mathrm{OH}_{\mathrm{ad}}\right)$ [30]. Therefore, the low catalytic activity developed by the commercial catalyst may be related to a low methanol adsorption, i.e. this catalyst does not present an optimized atomic arrangement on the surface. On the other hand, the Pt/Vulcan-EGM electrode presents the methanol oxidation peak at higher potentials than the others catalysts. The 
latter may be associated with certain difficulty of producing adsorbed oxygenated species (i.e. $\mathrm{OH}_{\mathrm{ad}}$ ) on the Pt/Vulcan-EGM surface.

With the purpose of evaluating the performance of the different electrodes as possible anodes for DMFCs, current transients were recorded at $0.55 \mathrm{~V}$ (a potential similar to that obtained during operating conditions in a fuel cell using only $\mathrm{Pt}$ as catalytic material) at room temperature in $0.5 \mathrm{M} \mathrm{H}_{2} \mathrm{SO}_{4}+0.1 \mathrm{M} \mathrm{CH}_{3} \mathrm{OH}$. In these experiments, the potential was steeped from $0.1 \mathrm{~V}$ (a potential where the methanol oxidation is negligible) to $0.55 \mathrm{~V}$. As can be seen in Fig. 11, the synthesis method has an important influence on the electrocatalytic activity towards the MOR. The electrode prepared by $\mathrm{BM}$ is the most active and develops a stationary current of ca. $3,2 \mu \mathrm{Acm}^{-2}$, which is around twice higher than the observed at the electrode Pt/Vulcan-EGM $\left(1.8 \mu \mathrm{Acm}^{-2}\right)$ and the commercial catalyst $\left(1.9 \mu \mathrm{Acm}^{-2}\right)$. In this sense, it is important to note that similar results were obtained by cyclic voltammetry (Fig. 10), in which the onset potential for methanol oxidation follows the same behaviour than the observed by the current transients (Fig. 11). Moreover, these results support the explanation suggested before, whereas the methanol adsorption and the formation of adsorbed oxygenated species on the commercial and Pt/Vulcan-EGM catalysts are inhibited, respectively. In the course of methanol oxidation experiments, mass signals of $\mathrm{CO}_{2}(\mathrm{~m} / \mathrm{z}=44)$ and formic acid (followed through methylformate formation $\mathrm{m} / \mathrm{z}=60$ ) were registered by the mass spectrometer with the purpose of calculating the $\mathrm{CO}_{2}$ conversion efficiency. Fig 12 shows the faradic current transients (black line) and the corresponding ionic current transients for $\mathrm{m} / \mathrm{z}=44$, for a selected electrode (E-TEK with 2 GDLs). Also it is included the faradic current expected for $100 \%$ efficient conversion of methanol to $\mathrm{CO}_{2}$ calculated from the $\mathrm{m} / \mathrm{z}=44$ signals after the calibration procedure (red line). 
The $\mathrm{CO}_{2}$ value for the conversion efficiency was close to $100 \%$ in agreement with previous reported DEMS analysis for carbon supported catalysts [9]. Under restricted diffusion conditions, like in the carbon-supported catalysts, the soluble by-products can interact again with the surface and be fully oxidized. As a consequence, the amount of adsorbed $\mathrm{CO}$ or other adsorbed species increases during the complete oxidation processes and, accordingly, the $\mathrm{CO}_{2}$ efficiency. The other electrodes presented similar results, with a $\mathrm{CO}_{2}$ conversion efficiency close to $100 \%$, except for the electrode synthesized by the EG method, whose efficiency was of $86 \%$.(see Tab. 2)

With the purpose of studying the GDL effect during the methanol oxidation reaction in a typical potential value for PEMFC in operation, several chronoamperometry experiments were carried out and the reaction intermediates and products were followed by in-situ DEMS. Fig. 13 shows the faradaic current transients (black line) and the corresponding ionic current transients for $\mathrm{CO}_{2}(\mathrm{~m} / \mathrm{z}=44)$ production (red line) recorded during the methanol oxidation on an E-TEK catalyst with different diffusion conditions (i.e. $1 \mathrm{GDL}, 2 \mathrm{GDL}$, commercial GDL). It is proved that the mass detection times are similar to those observed during the hydrogen evolution experiments (Fig. 3 and Fig. 4), i.e. the DEMS cell setup works appropriately and the delay for detecting a volatile molecule is less than $1 \mathrm{~s}$. (even working with the commercial GDL). On the other hand, the mass signal decay (i.e. after switch the working potential from 0.55 to $0.1 \mathrm{~V}$ ) is slower compared to the $\mathrm{H}_{2}$ experiments. As in the case of $\mathrm{CO}$ electrooxidation, this effect can be explained in terms of the slow $\mathrm{CO}_{2}$ diffusion away from the GDE, which contrasts with the fast hydrogen diffusion. This suggestion is clearly observed in Fig. 13, whereas the $\mathrm{CO}_{2}$ diffusion time decreases in the following order: commercial GDL $>2$ GDLs > 1 GDL, being 43, 33 and 28 s, respectively, the time necessary for achieving a decrease in the faradic current density of $70 \%$. It is remarkable, that these 
results are in concordance with those obtained during $\mathrm{CO}$ stripping and $\mathrm{H}_{2}$ evolution experiments.

\section{Conclusions}

A new configuration of the DEMS cell has been developed to characterize gas diffusion electrodes for fuel cells prepared with catalysts synthesized by different methods. This design has demonstrated to be appropriated for simultaneous evaluating of the catalytic and the diffusion properties of GDEs. In this way, it is possible to determinate the reaction products during $\mathrm{CO}$ and methanol electrooxidation reactions at carbon supported Pt catalysts used in GDEs. In addition, with the aid of DEMS calibration, it is possible to evaluate the efficiency for $\mathrm{CO}_{2}$ conversion.

Problems associated to the detection time of the spectrometer are not been found along the experiments, being the response time for the $\mathrm{CO}$ and methanol oxidation products similar to the observed with the hydrogen evolution experiment.

On the other hand, it is observed that the diffusion of $\mathrm{CO}_{2}$ formed during the $\mathrm{CO}$ stripping experiments or during the MOR was slower than that of hydrogen. It was observed that with two gas diffusion layers and with the commercial layer the diffusion time of the products was slower, but with only one diffusion layer (i.e. shorter diffusion path), results improved indicating that it is possible to control the diffusion properties of the electrodes. 
$\mathrm{CVs}$ and MSCVs recorded during the CO stripping oxidation showed an enhanced $\mathrm{CO}$ tolerance of Pt/Vulcan catalysts compared with the commercial E-TEK material. However, no significant differences were observed between the Pt/Vulcan electrodes synthesized by BM and EGM. Thus, CO stripping experiments seem to bring up the similarities of Pt/Vulcan (BM and EGM) electrodes towards the water dissociation (i.e. production of oxygenated species), which is favoured on these surfaces compared with that of the commercial catalyst.

Conversely, the behaviour of the catalysts for methanol oxidation was significantly different, being the electrode prepared by the BM the most catalytic. It is observed that all the electrodes presented similar $\mathrm{CO}_{2}$ conversion efficiencies $(\sim 100 \%)$, except for the electrode synthesized by the EG method, whose efficiency was of $86 \%$. The high values of $\mathrm{CO}_{2}$ conversion efficiencies are related to the re-adsorption and re-oxidation of by-side products. Nevertheless, the electrode synthesized by the EGM shows the lowest $\mathrm{CO}_{2}$ conversion efficiency, which is associated to a higher formation of by-side products (e.g. formic acid and formaldehyde).

In conclusion, methanol study shows the importance of a suitable surface towards methanol adsorption and dehydrogenation. In fact, Pt/Vulcan (BM and EGM) materials present similar behaviour towards $\mathrm{CO}$ oxidation, nevertheless the catalytic activity towards the methanol oxidation is completely different, i.e. both catalysts present similar activity sites towards water dissociation, but their surfaces for methanol adsorption and oxidation are different.

\section{Acknowledgments}


This work has been supported by the Gobierno de Aragón and Obra Social LaCaixa under project GA-LC-008/2009 and by the Gobierno de Canarias under project PI2007/023. S. Pérez-Rodríguez also acknowledges Gobierno de Aragón for their DGA grant. G. García acknowledges to the JAE program (CSIC) for financial support.

\section{References}

[1] Vielstich W, Gasteiger HA, A. Lamm A. Handbook of Fuel Cells: Fundamentals, Technology and Applications, New York: Willey; 2003.

[2] Wee J-H, Lee K-Y, Kim SH. Fabrication methods for low-Pt-loading electrocatalysts in proton exchange membrane fuel cell systems. J. Power Sources 2007; 165 (2): 667-77.

[3] $\mathrm{Yu} \mathrm{X}, \mathrm{Ye} \mathrm{S}$. Recent advances in activity and durability enhancement of $\mathrm{Pt} / \mathrm{C}$ catalytic cathode in PEMFCPart I. Physico-chemical and electronic interaction between $\mathrm{Pt}$ and carbon support, and activity enhancement of Pt/C catalyst. J. Power Sources $2007 ; 172 ; 133-44$.

[4] Álvarez G, Alcaide F, Cabot PL, Lázaro MJ, Pastor E, Solla-Gullón J. Electrochemical performance of low temperature PEMFC with surface tailored carbon nanofibers as catalyst support. Int. J. Hydrogen Energy 2011; ISSN 0360-3199, 10.1016/j.ijhydene.2011.09.055.

[5] Esmaeilifar A, Rowshanzamir S, Eikani MH, Ghazanfari E. Synthesis methods of low-Pt-loading electrocatalysts for proton exchange membrane fuel cell Systems. Energy 2010; 35: 3941-57.

[6] Planes GA, García G, Pastor E. High performance mesoporous Pt electrode for methanol electrooxidation. A DEMS study. Electrochem. Commun. 2007; 9: 839-44. 
[7] García G, Baglio V, Stassi A, Pastor E, Antonucci V, Aricò AS. Investigation of Pt$\mathrm{Ru}$ nanoparticle catalysts for low temperature methanol electro-oxidation. J. Solid State Electrochem. 2007; 11: 1229-38.

[8] García G, Silva-Chong JA, Guillén-Villafuerte O, Rodríguez JL, González ER, Pastor E. CO tolerant catalysts for PEM fuel cells: Spectroelectrochemical studies. Catal. Today 2006; 116: 415-21.

[9] García G, Florez-Montaño J, Hernandez-Creus A, Pastor E, Planes GA. Methanol electrooxidation at mesoporous $\mathrm{Pt}$ and Pt-Ru electrodes: A comparative study with carbon supported materials, J. Power Sources 2011; 196 (6): 2979-86.

[10] Antolini E, Salgado JRC, Santos LGRA, García G, Ticianelli EA, Pastor E, González ER. Carbon Supported Pt-Cr Alloys as Oxygen-Reduction catalysts for Direct Methanol fuel cells. J. Appl. Electrochem. 2006; 36: 355-62.

[11] Souza MVM, Ribeiro NFP, Schmal M. Influence of the support in selective CO oxidation on Pt catalysts for fuel cell applications, Int. J. Hydrogen Energy 2007; 32: 425-9.

[12] Ayastuy JL, Gurbani A, González-Marcos MP, Gutiérrez-Ortiz MA. Effect of copper loading on copper-ceria catalysts performance in $\mathrm{CO}$ selective oxidation for fuel cell applications. Int. J. Hydrogen Energy 2010; 35 (3): 1232-44.

[13] Abaoud HA, Ghouse M, Lovell KV, Al-Motairy GN. A hybrid technique for fabricating PEMFC's low platinum loading electrodes. Int. J. Hydrogen Energy 2005; 30 (4): $385-91$.

[14] Sebastián D, Calderón JC, González-Expósito JA, Pastor E, Martínez-Huerta MV, Suelves I, Moliner R, Lázaro MJ. Influence of carbon nanofiber properties as electrocatalyst support on the electrochemical performance for PEM fuel cells. Int. J. Hydrogen Energy 2010; 35 (18): 9934-42. 
[15] García G, Bruno MM, Planes GA, Rodríguez JL, Barbero CA, Pastor E. Probe beam deflection studies of nanostructured catalyst materials for fuelcells. Phys. Chem. Chem. Phys. 2008; 10: 6677-85.

[16] Zhigang Qi. PEM Fuel Cell Electrocatalysts and Catalyst Layers: Fundamentals and applications. 1st ed. London: Springer; 2008.

[17] Cuccaro R, Lucariello M, Battaglia A, Graizzaro A. Research of a HySyLab internal standard procedure for single PEMFC. Int. J. Hydrogen Energy 2008; 33 (12): 3159-66.

[18] Jusys Z, Behm RJ. Simultaneous oxygen reduction and methanol oxidation on a carbon-supported Pt catalyst and mixed potential formation-revisited Electrochim. Acta 2004; 49: 3891-3900.

[19] Wang H, Wingender Ch, Baltruschat H, Lopez M, Reetz MT. Methanol oxidation on Pt, PtRu and colloidal Pt electrocatalysts: A DEMS study of product formation. J. Electroanal. Chem. 2001; 509: 163-9.

[20] Wang H, Rus E, Abruña HD. New Double-Band-Electrode channel flow differential electrochemical mass spectrometry cell: application for detecting product formation during methanol electrooxidation. Anal. Chem. 2010; 82: 4319-24.

[21] Wolter O, Heitbaum J, Bunsenges Ber. Differential Electrochemical Mass Spectroscopy (DEMS) — a New Method for the Study of Electrode Processes, Phys. Chem. 1984; 88: 2-6.

[22] Baltruschat H. Differential electrochemical mass spectrometry. J. American Soc. Mass Spectrometry 2004; 15: 1693-1706.

[23] Calvillo L, Lázaro MJ, García-Bordejé E, Moliner R, Cabot PL, Esparbé I, Pastor E, Quintana JJ. Platinum supported on functionalized ordered mesoporous carbon as electrocatalyst for direct methanol fuel cells. J. Power Sources 2007; 169: 59-64. 
[24] Wang X, Hsing IM. Surfactant stabilized Pt and Pt alloy electrocatalyst for polymer electrolyte fuel cells. Electrochim. Acta 2002; 47: 2981-87.

[25] Wolter O, Heitbaum J. Differential Electrochemical Mass Spectroscopy (DEMS) a New Method for the Study of Electrode Processes. Bunsenges Ber. Phys. Chem. 1984; $88,2-6$.

[26] Wasmus S, Samms SR, Savinell RF. Multipurpose Electrochemical Mass Spectrometry: A new powerful Extension of Differential Electrochemical Mass Spectrometry. J. Electrochem. Soc. 1995; 142: 1183-89.

[27] Souza JPI, Queiroz SL, Nart FC. Uso de espectrometria de massas em medidas electroquímicas - a técnica de DEMS. Quim. Nova 2000; 23: 384-91.

[28] Lin R, Cão C, Zhang H, Huang H, Ma J. Electro-catalytic activity of enhanced CO tolerant cerium-promoted Pt/C catalyst for PEM fuel cell anode. Int. J. Hydrogen Energy 2011, ISSN 0360-3199, 10.1016/j.ijhydene.2011.05.021.

[29] Chaparro AM, Martín AJ, Folgado MA, Gallardo B, Daza L. Comparative analysis of the electroactive area of Pt/C PEMFC electrodes in liquid and solid polymer contact by underpotential hydrogen adsorption/desorption. Int. J. Hydrogen Energy 2009 ; 34 (11) : 4838-46.

[30] Aricò AS, Srinivasan S, Antonucci V. DMFCs: From Fundamental Aspects to Technology Development. Fuel Cells 2001; 1: 133-61.

[31] Chen Y, Zhang G, Ma J, Zhou Y, Tang Y, Lu T. Electro-oxidation of methanol at the different carbon materials supported Pt nano-particles. Int. J. Hydrogen Energy 2010; 35 (19): 10109-17.

[32] Tsai M-C, Yeh T-K, Tsai C-H, Methanol oxidation efficiencies on carbonnanotube-supported platinum and platinum-ruthenium nanoparticles prepared by pulsed electrodeposition. Int. J. Hydrogen Energy 2011; 36 (14): 8261-66. 
Tables, Figures and Captions.

Table. 1. Nomenclature of the gas diffusion electrodes.

\begin{tabular}{|c|c|c|}
\hline Electrode & Synthesis method & Diffusion conditions \\
\hline Pt/Vulcan-BM & BM & 2 GDLs \\
\hline Pt/Vulcan-EGM & EGM & 2 GDLs \\
\hline E-TEK & -- & 2 GDLs \\
\hline E-TEK 1GDL & -- & GDL \\
\hline E-TEK Commercial GDL & -- & Commercial GDL \\
\hline
\end{tabular}

Table. 2. $\mathrm{CO}_{2}$ conversion efficiency for methanol oxidation on Pt electrodes obtained at $0.55 \mathrm{~V}$ under no flow conditions.

\begin{tabular}{|c|c|}
\hline Electrode & $\mathbf{C O}_{\mathbf{2}}$ conversion efficiency (\%) \\
\hline Pt/Vulcan-BM & 98 \\
\hline Pt/Vulcan-EGM & 86 \\
\hline E-TEK & 93 \\
\hline
\end{tabular}


Fig. 1. Scheme of the DEMS cell

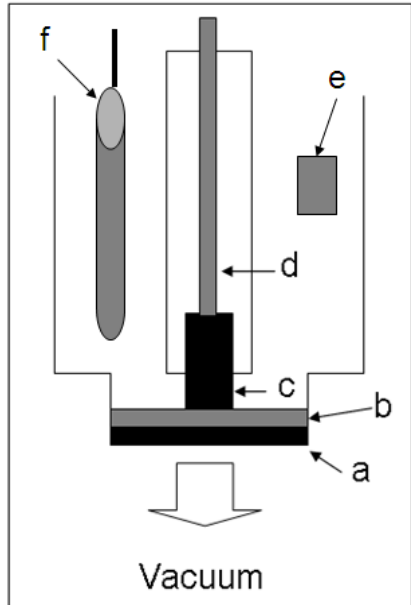

a. Membrane to detector

b. Working electrode

c. Glassy carbon disk

d. Au wire

e. Counter electrode

f. RHE 
Fig. 2. XRD pattern of Pt/Vulcan-EGM catalyst.

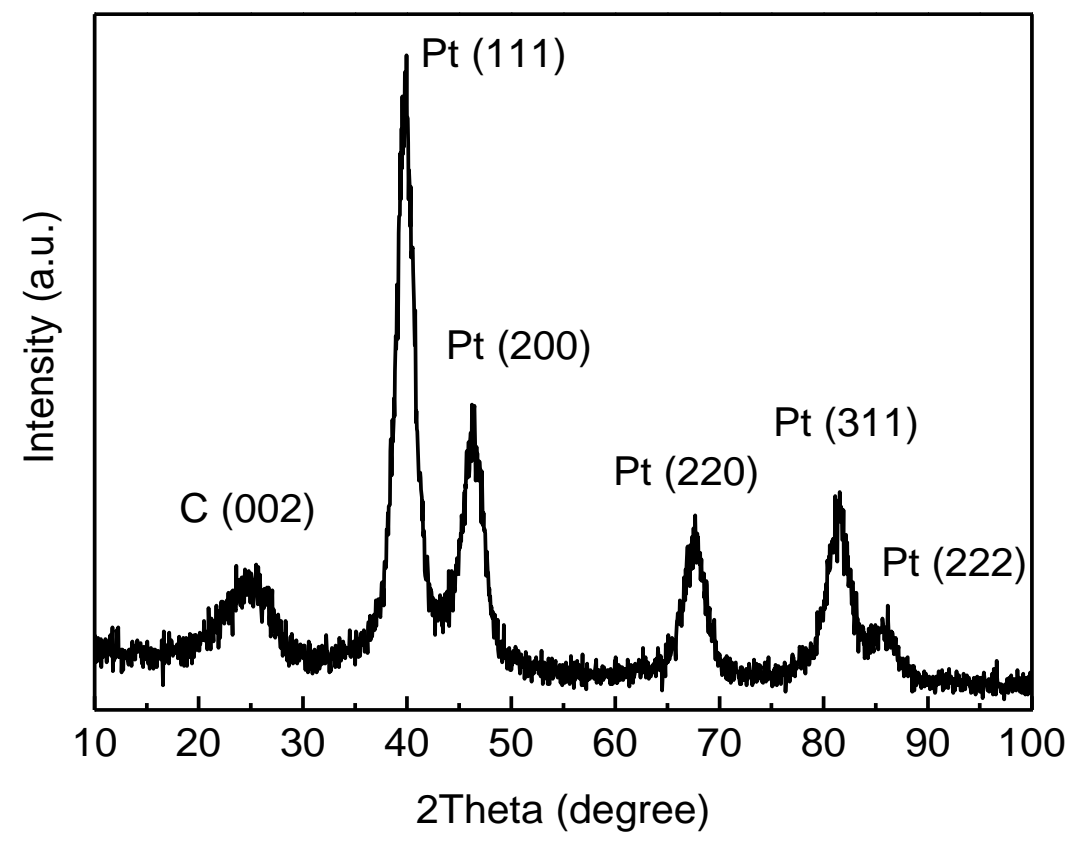


Fig. 3. (black line) $\mathrm{CT}$ and (red line) MSCTs for hydrogen, $\mathrm{m} / \mathrm{z}=2$ from $0,4 \mathrm{~V}$ to $0 \mathrm{~V}$ vs. RHE onto E-TEK electrode with two gas diffusion layers. $0.5 \mathrm{M} \mathrm{H}_{2} \mathrm{SO}_{4}$.

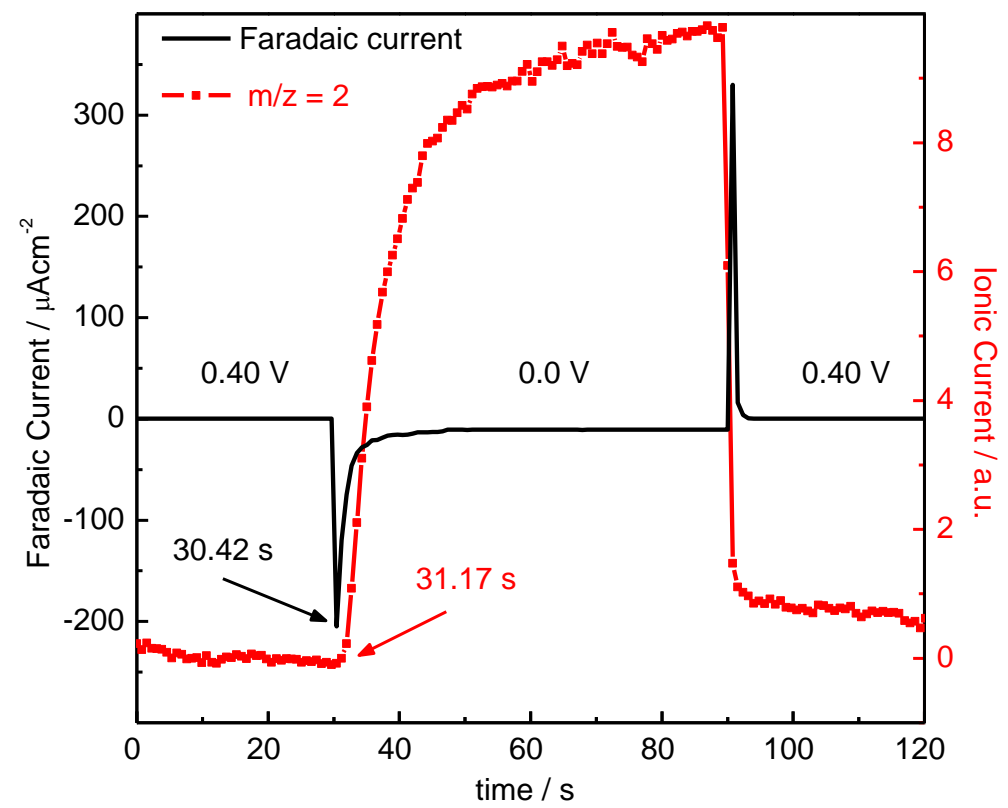


Fig. 4. (black line) CT and (red line) MSCTs for hydrogen, $\mathrm{m} / \mathrm{z}=2$ from $0,4 \mathrm{~V}$ to $0 \mathrm{~V}$ vs. RHE onto E-TEK electrode with one gas diffusion layer (A) and with a commercial gas diffusion layer (B). $0.5 \mathrm{M} \mathrm{H}_{2} \mathrm{SO}_{4}$.

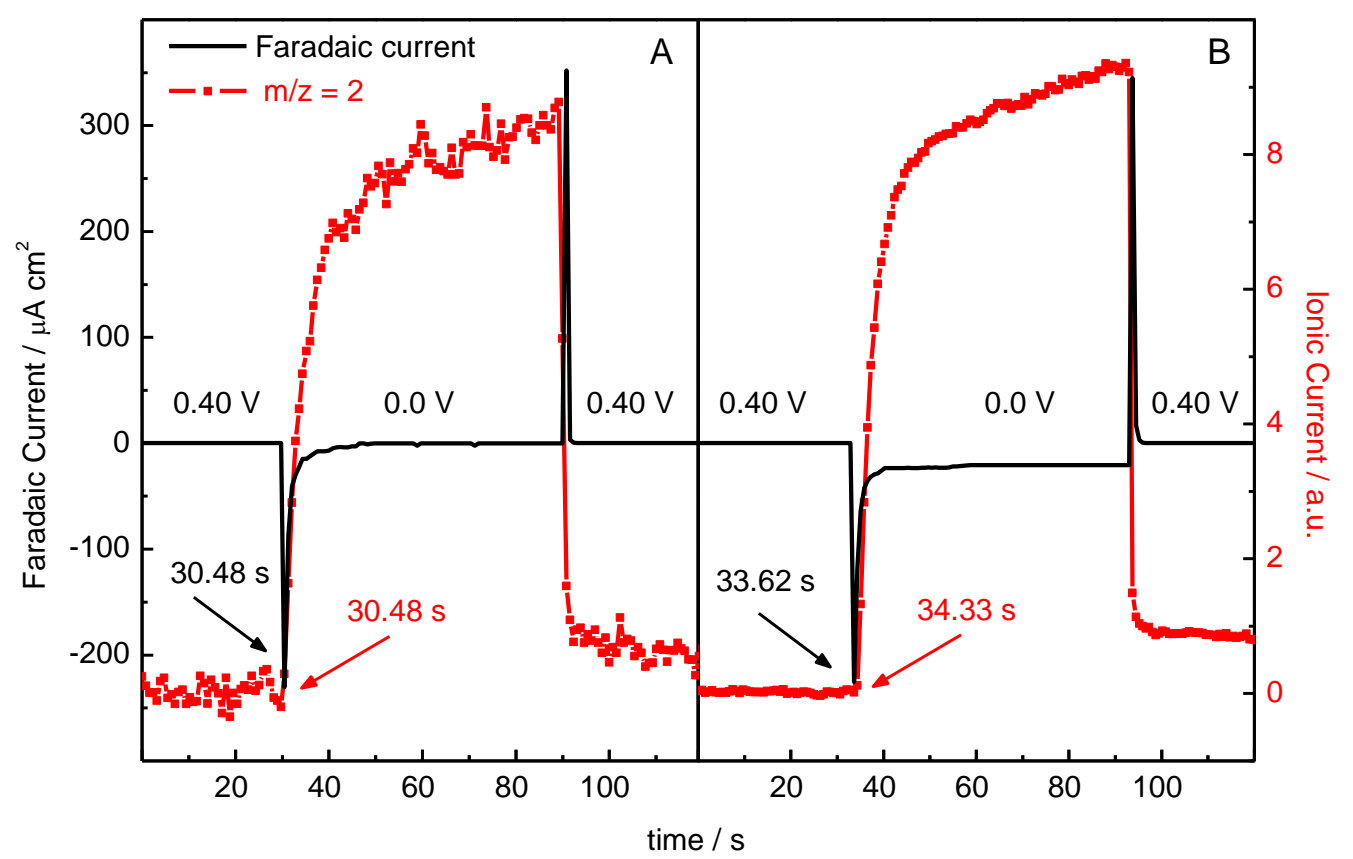


Fig. 5. (upper panel) CV, (middle panel) current density and (bottom panel) mass signal for $\mathrm{H}_{2}(\mathrm{~m} / \mathrm{z}=2)$ vs. time on Pt/Vulcan-BM, E-TEK and Pt/Vulcan-EGM electrodes. $v=$ $0.01 \mathrm{Vs}^{-1}, 0.5 \mathrm{M} \mathrm{H}_{2} \mathrm{SO}_{4}$.

Potential / V vs. REH

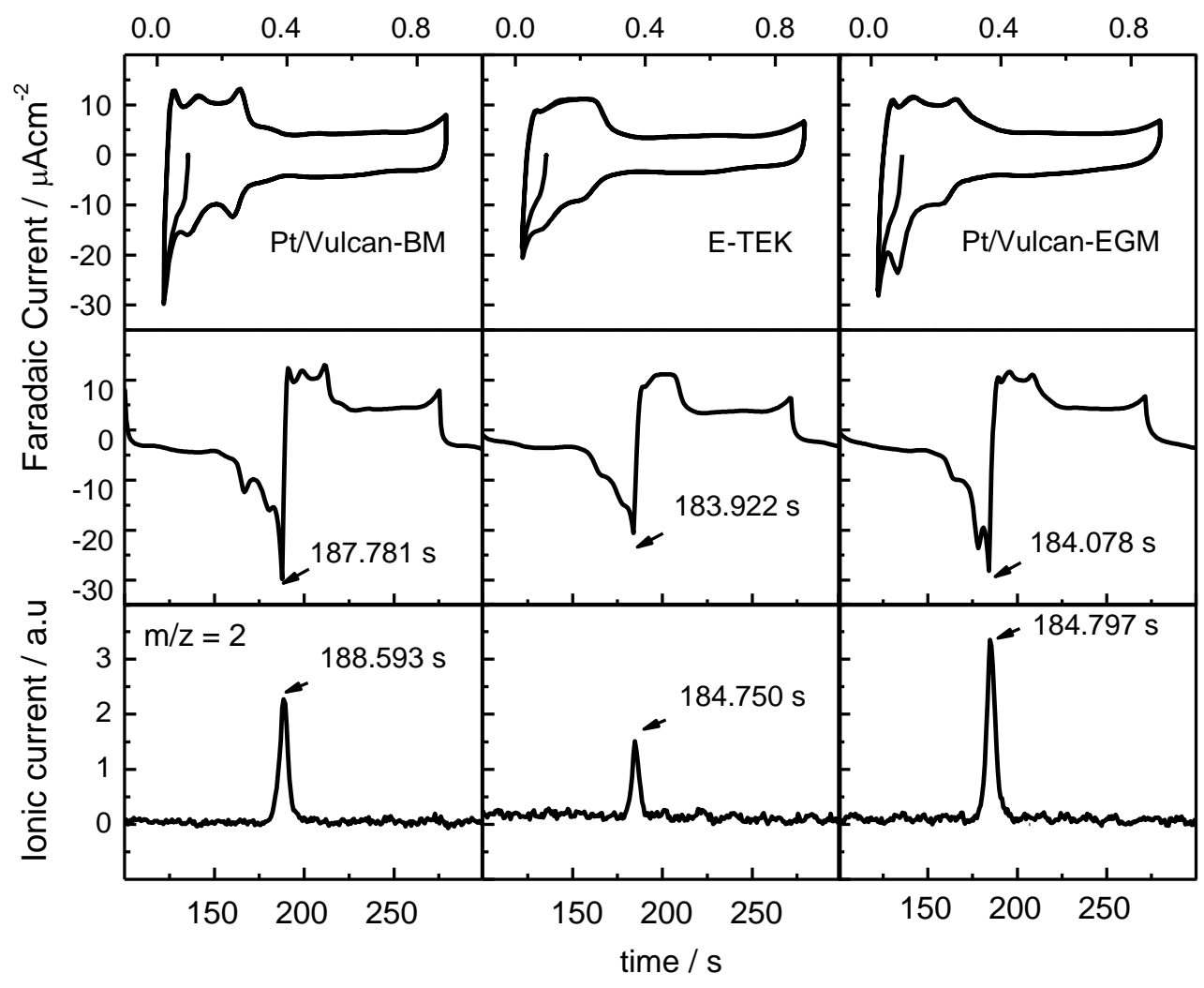


Fig. 6. (upper panel) CV, (middle panel) current density and (bottom panel) mass signal for $\mathrm{H}_{2}(\mathrm{~m} / \mathrm{z}=2)$ vs. time on E-TEK electrode with one diffusion layer at different scan rates $\left(v=0.01,0.02\right.$ and $\left.0.05 \mathrm{Vs}^{-1}\right), 0.5 \mathrm{M} \mathrm{H}_{2} \mathrm{SO}_{4}$.

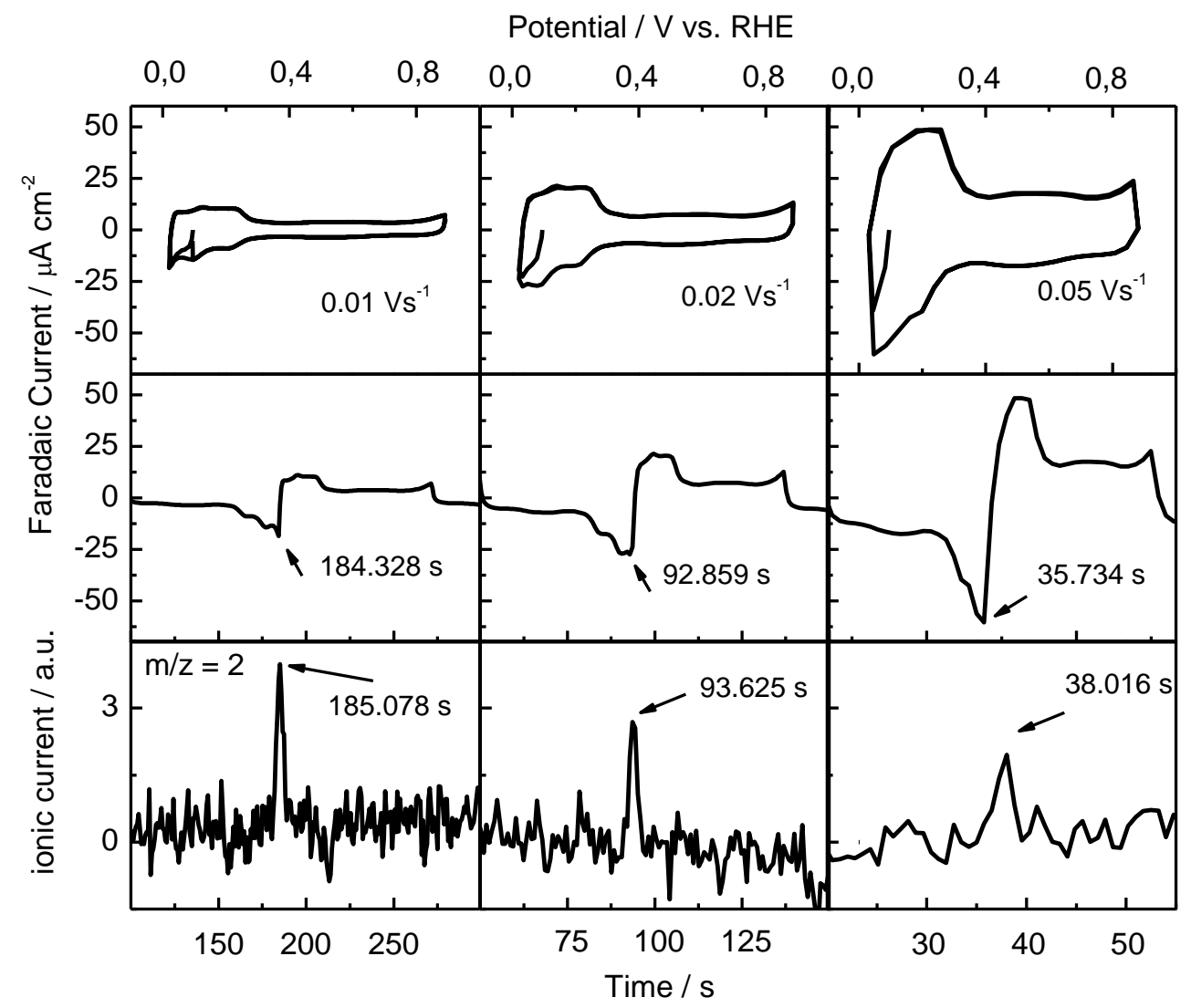


Fig. 7. (upper panel) CV, (middle panel) current density and (bottom panel) mass signal for $\mathrm{H}_{2}(\mathrm{~m} / \mathrm{z}=2)$ vs. time on E-TEK electrode with one diffusion layer at $0.005 \mathrm{Vs}^{-1}, 0.5$ $\mathrm{M} \mathrm{H}_{2} \mathrm{SO}_{4}$.

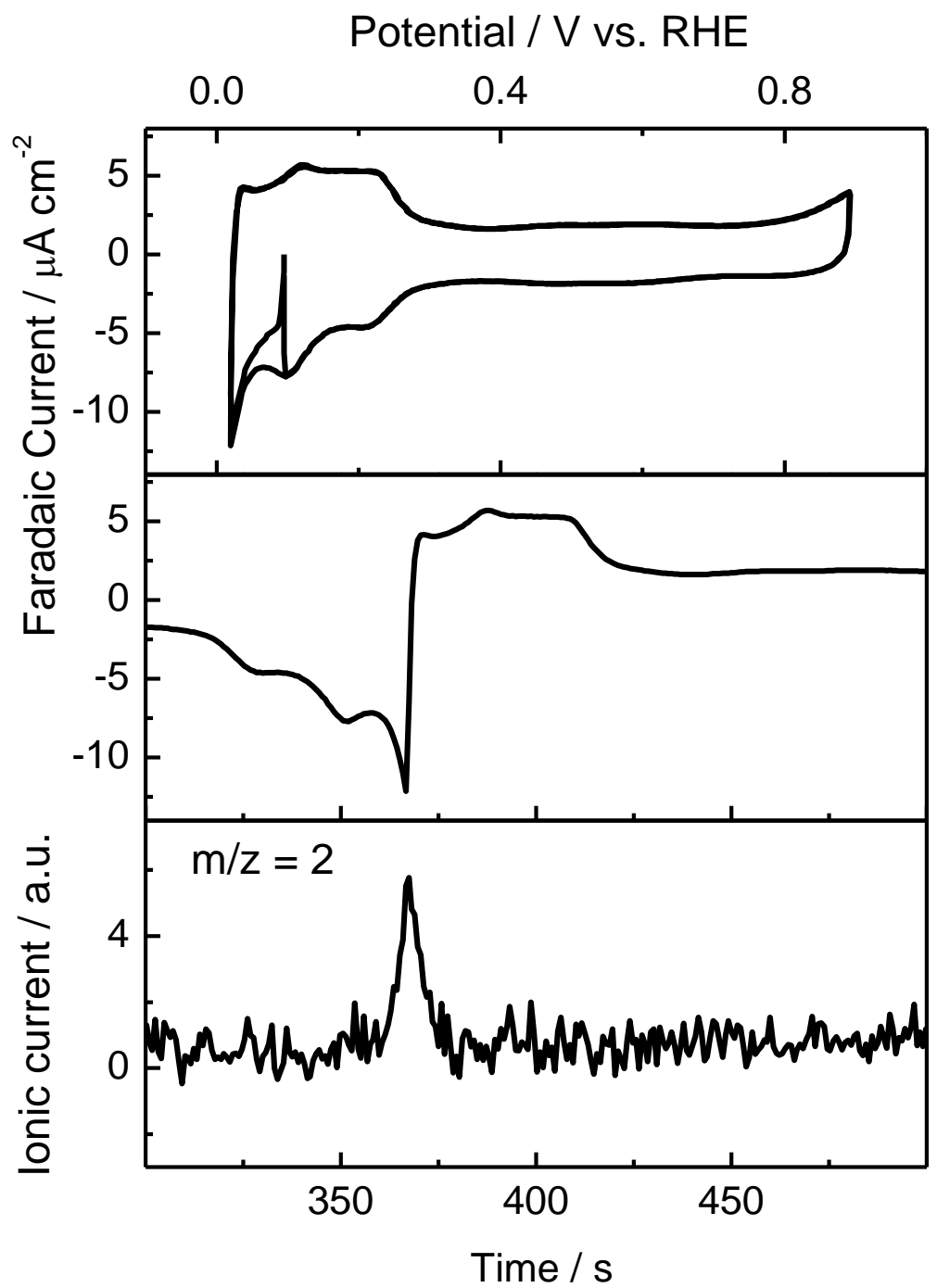


Fig. 8. CO stripping voltammograms on Pt/Vulcan electrodes with two gas diffusion layers at $0.005 \mathrm{Vs}^{-1}, 0.5 \mathrm{M} \mathrm{H}_{2} \mathrm{SO}_{4}$.

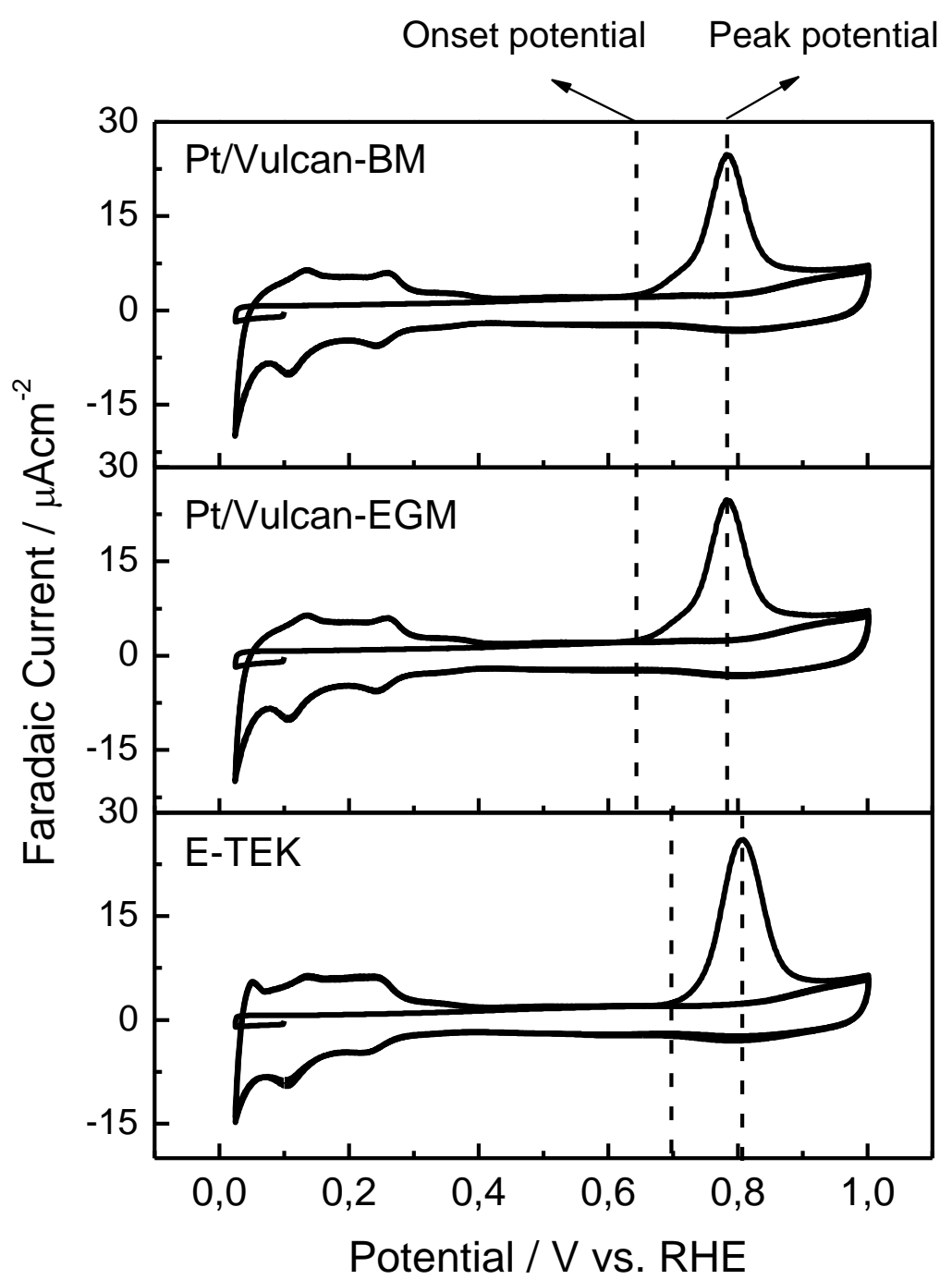


Fig. 9. (upper panel) CO stripping voltammogram, (middle panel) current density and (bottom panel) mass signal for $\mathrm{CO}_{2}(\mathrm{~m} / \mathrm{z}=44)$ vs. time on E-TEK electrode with different diffusion conditions (2GDL, $1 \mathrm{GDL}$ and a commercial GDL) at $0.005 \mathrm{Vs}^{-1}, 0.5$ $\mathrm{M} \mathrm{H}_{2} \mathrm{SO}_{4}$.

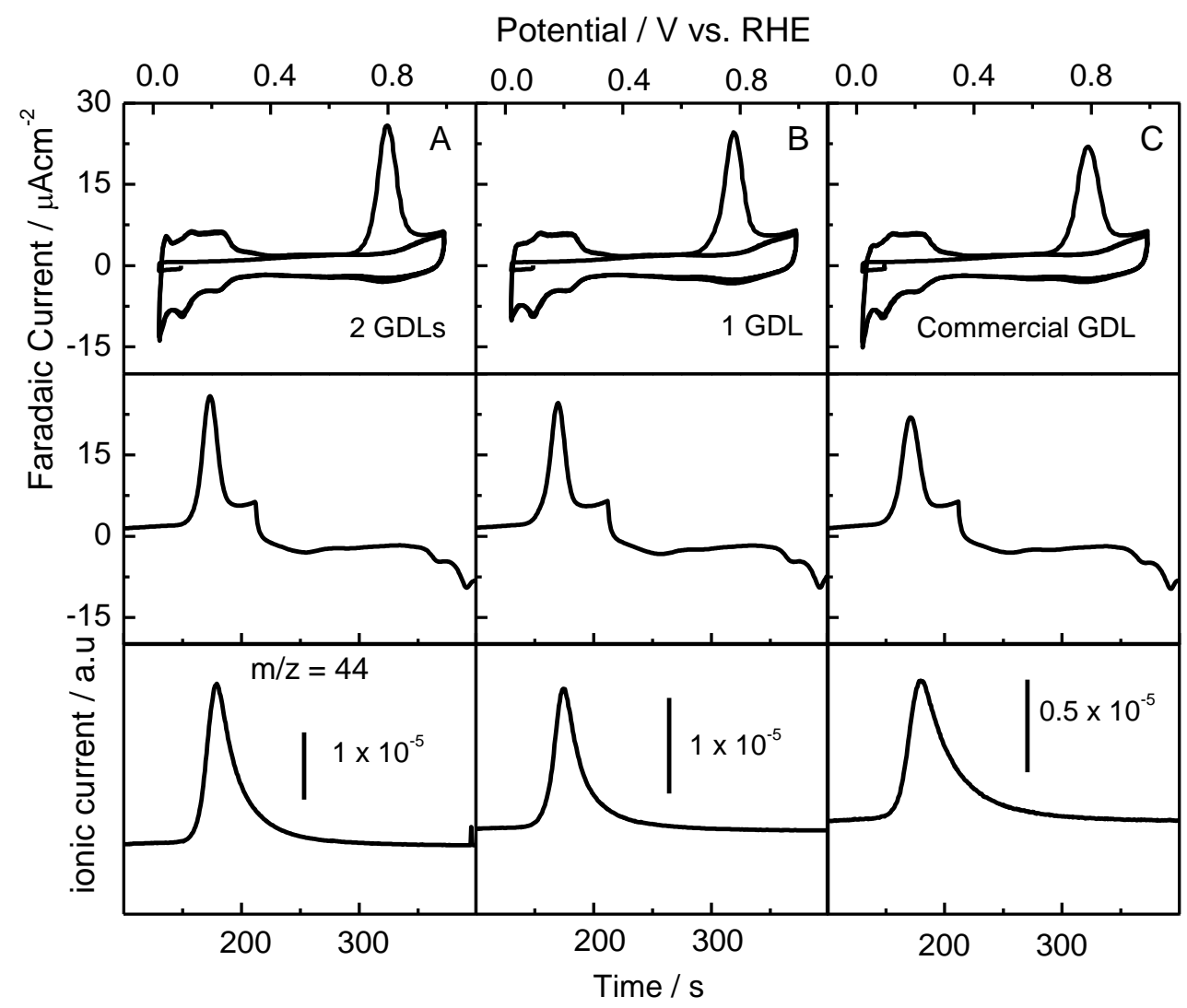


Fig. 10. CVs on Pt electrodes with 2 gas diffusion layers at $0.005 \mathrm{Vs}-1,0.5 \mathrm{M} \mathrm{H}_{2} \mathrm{SO}_{4}+$ $0.1 \mathrm{M} \mathrm{CH}_{3} \mathrm{OH}$.

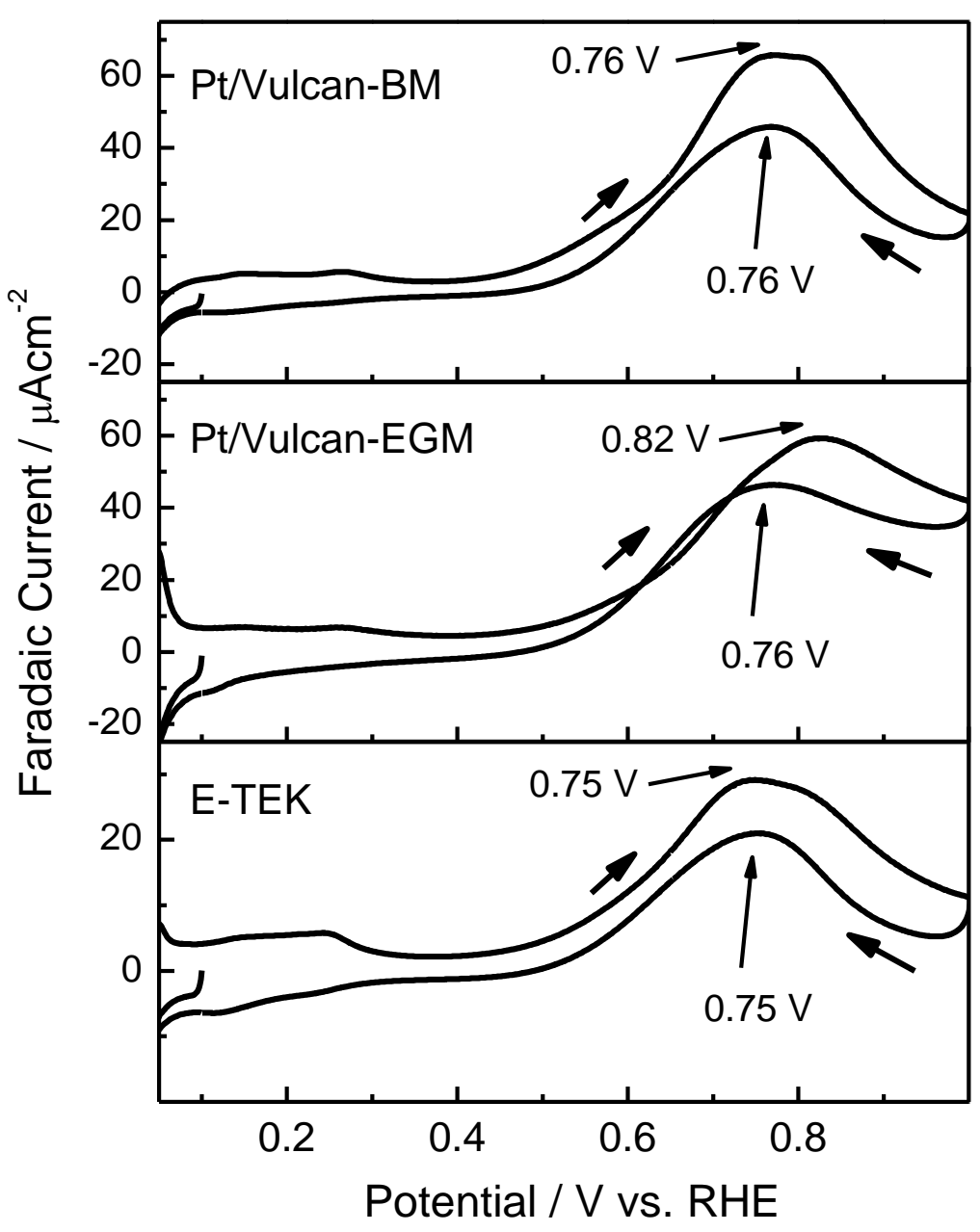


Fig. 11. CTs on Pt electrodes with 2 gas diffusion layers from $0.1 \mathrm{~V}$ to $0.55 \mathrm{~V}, 0.5 \mathrm{M}$ $\mathrm{H}_{2} \mathrm{SO}_{4}+0.1 \mathrm{M} \mathrm{CH}_{3} \mathrm{OH}$.

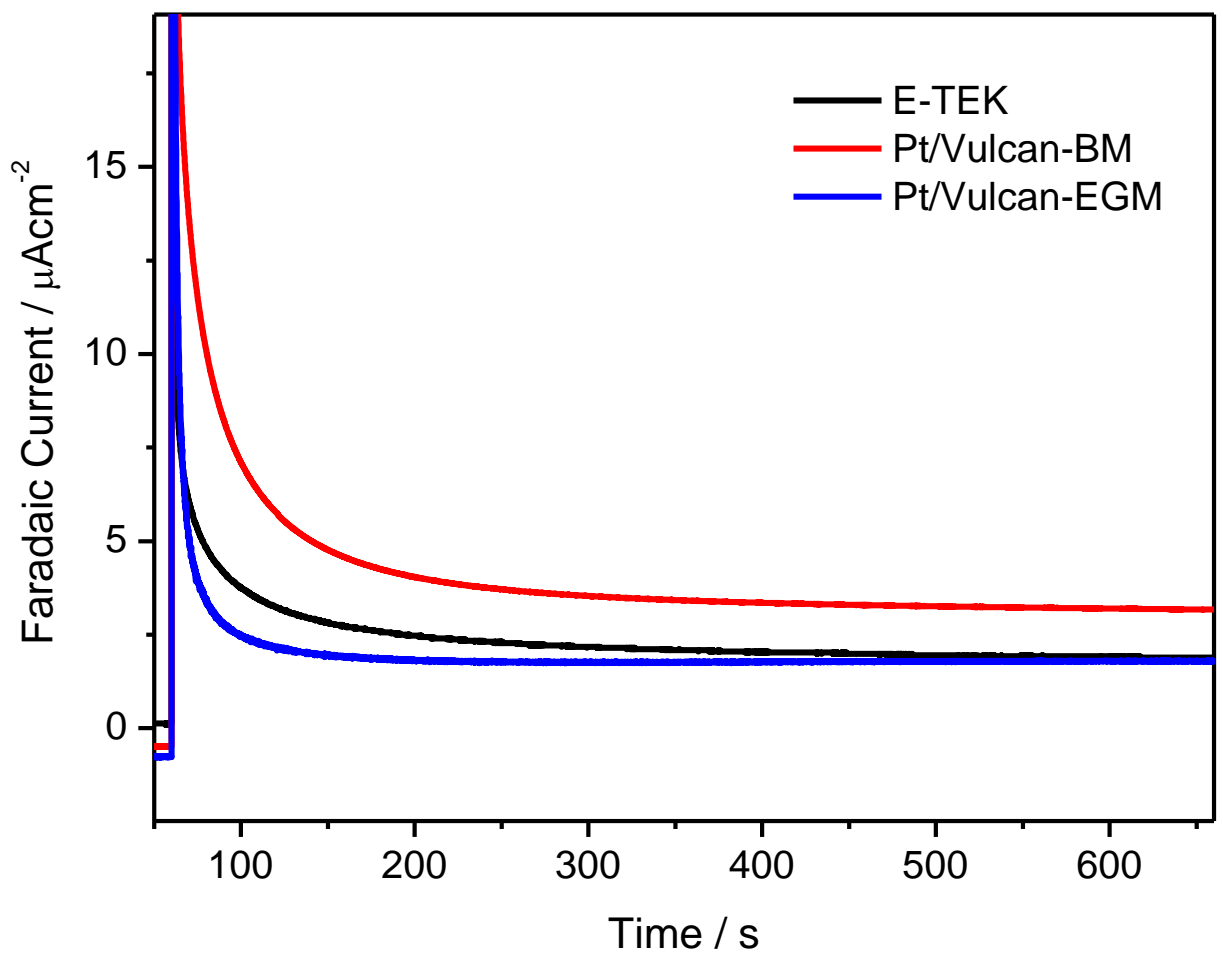


Fig. 12. (black line) CTs and MSCTs for $\mathrm{CO}_{2}(\mathrm{~m} / \mathrm{z}=44)$ from 0.1 to $0.55 \mathrm{~V}$ vs. RHE onto E-TEK electrode with $2 \mathrm{GDL}$ and (red line) current calculated from $\mathrm{CO}_{2}$ signal $(\mathrm{m} / \mathrm{z}=44), 0.5 \mathrm{M} \mathrm{H}_{2} \mathrm{SO}_{4}+0.1 \mathrm{M} \mathrm{CH}_{3} \mathrm{OH}$.

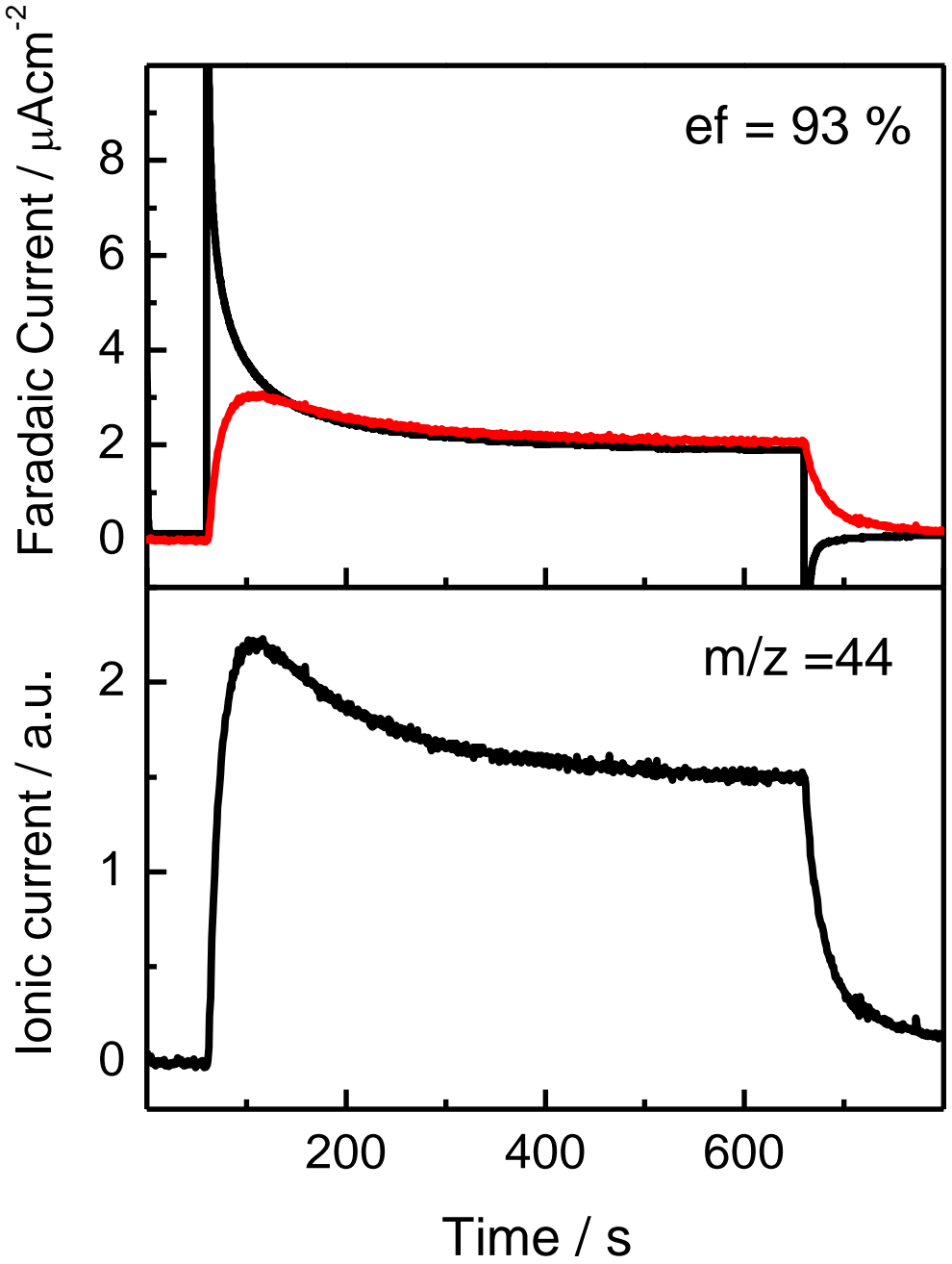


Fig. 13. (black line) CTs and (red line) MSCTs for $\mathrm{CO}_{2}(\mathrm{~m} / \mathrm{z}=44)$ from 0.1 to $0.55 \mathrm{~V}$ vs. RHE onto E-TEK electrode with different diffusion conditions (2GDL, 1 GDL and a commercial GDL), $0.5 \mathrm{M} \mathrm{H}_{2} \mathrm{SO}_{4}+0.1 \mathrm{M} \mathrm{CH}_{3} \mathrm{OH}$.

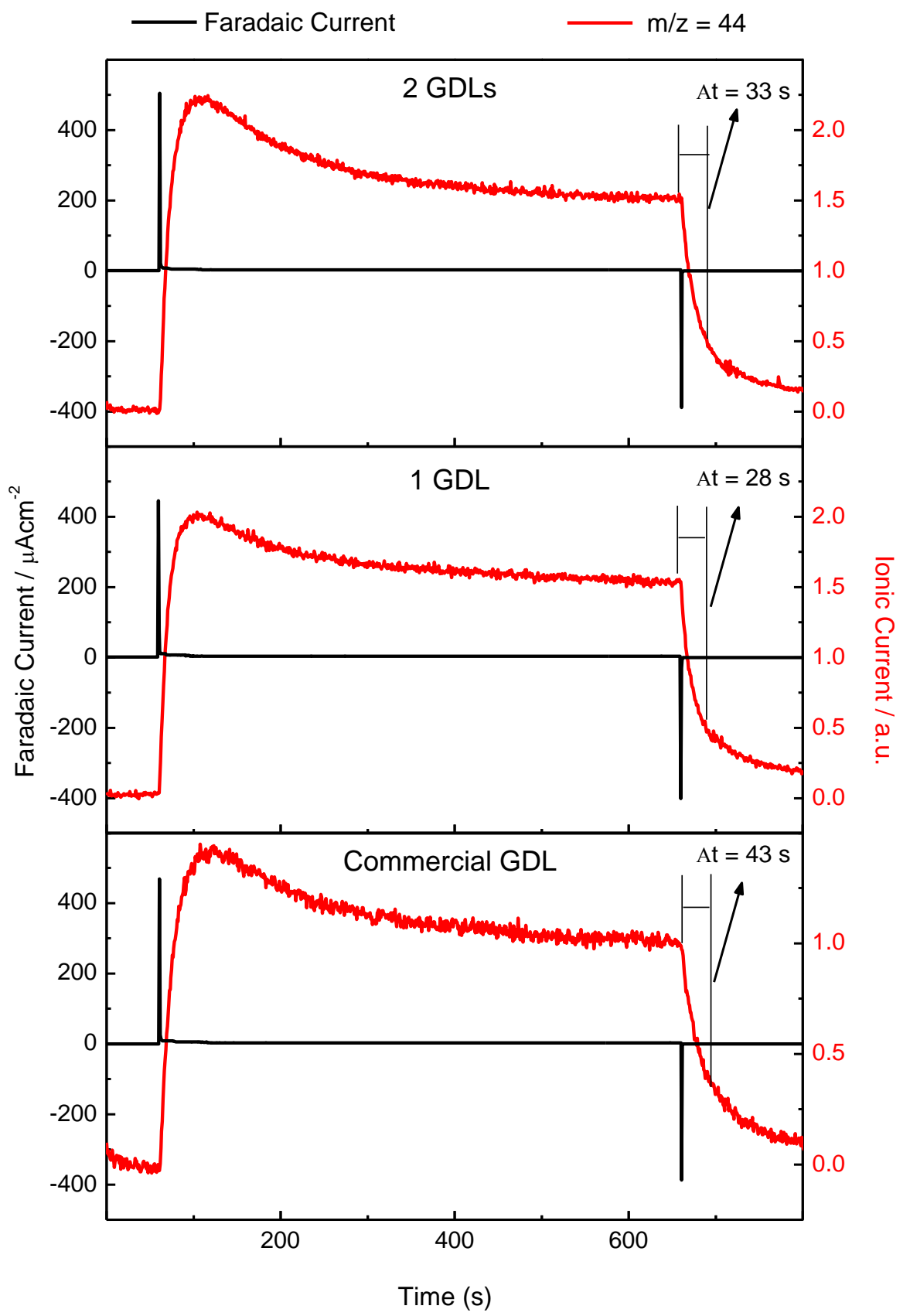

